\title{
ENHANCED POWER QUALITY COMPENSATION OF SHUNT ACTIVE POWER FILTERS WITHOUT HARMONIC DETECTION SCHEMES
}

\author{
Ricardo L. A. Ribeiro ${ }^{1}$, Raphaell. M. Sousa ${ }^{2}$, Euzeli C. dos Santos Jr. ${ }^{3}$, Thiago O. A. Rocha ${ }^{1}$ \\ Laboratório de Eletrônica de Potência e Energias Renováveis - UFRN ${ }^{1}$, Natal, RN - Brasil \\ Instituto Federal de Educação Ciência e Tecnologia da Paraíba ${ }^{2}$, Cajazeiras - Brasil \\ IUPUI, Purdue University Indianapolis ${ }^{3}$, Indianapolis, IN - Estados Unidos \\ e-mails:rlucio@ct.ufrn.br, raphaellmsousa@gmail.com, thiago.de.oliveira.alves.rocha@gmail.com, eudossan@iupui.edu
}

\begin{abstract}
Shunt active power filters $(S A P F)$ implemented without harmonic detection schemes compensate the harmonic distortion and reactive power of the load simultaneously. However, their compensation capabilities are limited by the $S A P F$ power converter rating. Such a restriction can be minimized if the level of the reactive power demanded by the $S A P F$ is managed. An estimation scheme for determining the filter currents is introduced to manage the level of reactive power compensation. The effectiveness of the proposed control strategy is ensured by introducing a feedforward scheme on the DC-link voltage regulation. In addition, a robust control based on adaptive pole placement with a variable structure scheme regulates the grid currents. Experimental results are shown for demonstrating the effectiveness of the proposed $S A P F$ system.
\end{abstract}

Keywords - Adaptive Control Strategy, Harmonic Compensation, Power Factor Correction, Selective Power Quality Compensation, Shunt Active Power Filter.

\section{LIST OF VARIABLES}

$\begin{array}{ll}v_{s 123} & \text { PCC three-phase voltages } \\ v_{f 123}^{*} & S A P F \text { Three-phase reference voltages } \\ v_{c} & \text { DC-Link voltage } \\ v_{c}^{*} & \text { DC-Link reference voltage } \\ v_{s d q}^{e} & \text { Grid } d q \text { phase voltages in rotational frame } \\ v_{f d q}^{e *} & S A P F d q \text { reference phase voltages in } \\ & \text { rotational frame } \\ i_{f q}^{e *} & S A P F \quad q \text {-phase reference current in } \\ \widehat{i}_{f q}^{e} & \text { rotational frame } \\ & S A P F \quad q \text {-phase estimated current in } \\ \widehat{\widehat{i}}_{f q}^{e} & \text { rotational frame } \\ & S A P F \text { average value of } q \text {-phase estimated } \\ i_{s q}^{e *} & \text { current in rotational frame } \\ & \text { Grid } q \text {-phase reference current in rotational } \\ i_{f d}^{e *} & \text { frame } \\ \hat{i}_{f d}^{e} & \text { rotational frame } \\ & S A P F \quad d \text {-phase estimated current in } \\ i_{s d}^{e} & \text { rotational frame } \\ & \text { Grid } d \text {-phase current in rotational frame }\end{array}$

Manuscript received 17/07/2013; revised 26/12/2013, second revised $23 / 11 / 2014$, accepted for publication $23 / 11 / 2014$ by recommendation of the Editor Henrique A. C. Braga.

$\begin{array}{ll}i_{s d}^{e *} & \begin{array}{l}\text { Grid } d \text {-phase reference current in } \\ \text { rotational frame } \\ i_{s d q}^{s}\end{array} \\ \begin{array}{l}\text { Grid } d q \text { phase currents in the stationary } \\ \text { frame }\end{array} \\ \theta_{s} & \text { Grid voltage vector angle } \\ i_{s d}^{s *} & \text { Grid } d \text {-phase reference current in the } \\ & \text { stationary frame } \\ i_{s q}^{s *} & \text { Grid } q \text {-phase reference current in the } \\ & \text { stationary frame } \\ i_{s d}^{s} & \text { Grid } d \text {-phase current in the stationary } \\ & \text { frame } \\ & \text { Grid } q \text {-phase reference current in the } \\ i_{s q}^{s} & \text { stationary frame } \\ & S A P F \quad d \text {-phase reference voltage in } \\ v_{f d}^{*} & \text { rotational frame } \\ & S A P F \quad q \text {-phase reference voltage in } \\ v_{f q}^{*} & \text { rotational frame }\end{array}$

\section{INTRODUCTION}

The growing use of nonlinear load as embedded dispositive in household, commercial or industrial electronic-based appliances has deteriorated the power quality of the mains. These loads can generate current harmonics and reactive power that end up with voltage drops on the supply network impedance, which can lead to unbalance conditions. Conventional solutions such as passive filters for reducing harmonic pollution are ineffective. Furthermore, the standards and recommendations that delimit the boundaries of harmonic distortion and reactive power in the power systems have become ever more restricted [1], [2], which has stimulated the use of active power compensation [3], [4].

Shunt active power filters $(S A P F)$ have been extensively used for compensation of harmonics, reactive power or unbalanced conditions [5]. The conventional control schemes applied to $S A P F$ are normally harmonic extractors based strategies $(H E B S)$. Their effectiveness depends on how quickly and accurately harmonic components of nonlinear loads are identified [6]. Harmonic extractors used in $H E B S$ can be implemented by using different approaches such as: traditional $d q$ method [7], $p q$ theory [8], adaptive filters [9], wavelet [10], genetic algorithm $(G A)$ [11] or artificial neural network $(A N N)$ [12]. The $S A P F$ can also be implemented without the use of load harmonic extractors. In this case, the harmonic compensation can be obtained from the power balance active system [13], [14], i.e., balanced energy based schemes $(B E B S)[14]$. 
The control systems of $S A P F$ implemented based on $H E B S$ or $B E B S$ methodologies are normally accomplished by a cascade strategy with both inner and outer control loops. The inner one regulates either the filter currents $(H E B S)$ or grid currents $(B E B S)$, while the outer control loop deals with $D C-$ link voltage regulation. The effectiveness of both methodologies depends on the performance of both control loops. In general, $P I$ controllers have been used for regulating the $D C-l i n k$ voltage on both approaches. However, other alternatives have been proposed, such as feedforward schemes [15] and adaptive control [16]. Regarding the current control strategies, PI controllers in the grid voltage vector reference frame have been employed as a standard solution [17]. Other solutions employ dead-beat control [18], sliding mode control [19], adaptive control [20], resonant control [21] or repetitivebased control [22]. When the $S A P F$ are implemented according to $B E B S$ methodology the current control strategy can be simplified by using only one resonant controller, tuned at the fundamental frequency [14].

Recently, an adaptive control strategy applied to $S A P F$ (using the $B E B S$ methodology) has been proposed for compensation of harmonic distortion, reactive power and unbalanced load [14]. As presented in [14] the current control is implemented by an adaptive pole placement control along with a variable structure scheme $(V S-A P P C)$. The main advantage of the proposed control strategy refers to the reduction of $S A P F$ complexity of implementation, resulting in reduced costs due to the no necessity of load and filter phase current measurements. However, this control scheme has two drawbacks: poor performance of the $D C$-link voltage control loop during the occurrence of severe load variations and, the necessity of simultaneous full compensation of the harmonic distortion and reactive power. Although full compensation at the point of common coupling $(P C C)$ is ideal, sometimes this may not be feasible due to the limited power rating of the $S A P F$ power converter.

This paper proposes a modification in the structure presented in [14] that improves $S A P F$ performance. In this new approach, a feedforward scheme, based on the estimation of filter currents is introduced in the $D C$-link voltage control loop. It anticipates the possible effects arising from severe load variations increasing the controller performance during these transients. Moreover, based upon the estimation of the $S A P F$ filter currents, it is proposed a new strategy that allows flexibility of reactive power compensation (for $B E B S$ methodology). Thus, it is possible to establish the weights of reactive power without violating the power rating limit imposed by the $S A P F$ power converter. The proposed control technique is very suitable for digital control. The effectiveness of the proposed control scheme is demonstrated throughout several experimental results.

\section{SYSTEM DESCRIPTION AND MODELING}

Figure II presents the schematic of the $S A P F$ used in the laboratory prototype. It comprises a three-phase grid source $\left(e_{s 123}\right)$ with its internal impedance $\left(Z_{s}=r_{s}+s l_{s}\right)$ that connects a three-phase load such a load is composed of parallel association of a non-controlled rectifier and a three-phase $R L$

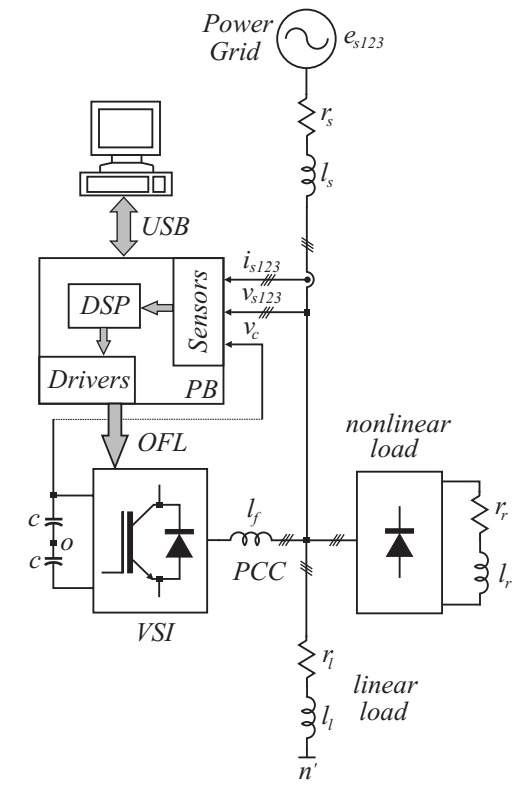

Fig. 1. Basic diagram of a shunt active power filter system connected to the power grid.

load $\left(Z_{l}=r_{l}+s l_{l}\right)$. The $S A P F$ is implemented by a voltage source inverter $(V S I)$ connected to $P C C$ through inductors $l_{f}\left(Z_{f}=r_{f}+s l_{f}\right.$, wherein $r_{f}$ is the intrinsic resistance of $l_{f}$ ). The control system is implemented by a digital signal processor $(D S P)$ connected to a plug-in board $(P B)$. The $P B$ is assembled with voltage and current sensors, as well as, the converter circuit drivers, which commands the power converter via optical fiber links $(O F L)$.

\section{A. System Modeling}

The $S A P F$ system can be represented by the per-phase equivalent circuit presented in Figure 2 [14].

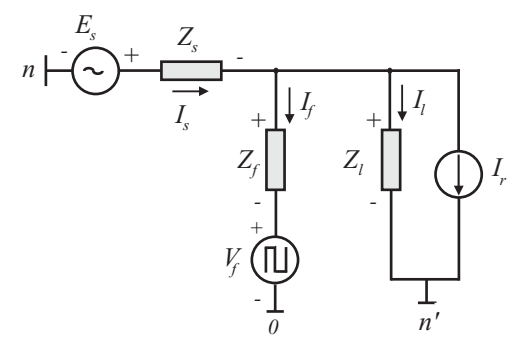

Fig. 2. Per-phase equivalent circuit of a shunt active power filter system.

In this circuit, the nonlinear load is represented by the current source $I_{r}$ that represents the distortions generated by the rectifier. From the equivalent circuit of Figure 2, the transfer function in $d q$ stationary reference frame can be given by

$$
\frac{I_{s d q}^{s \prime}(s)}{V_{f d q}^{s}(s)}=-\frac{r_{l}}{\gamma_{2}} \frac{\left(1+s \frac{l_{l}}{r_{l}}\right)}{s^{2}+\frac{\gamma_{1}}{\gamma_{2}} s+\frac{\gamma_{0}}{\gamma_{2}}}
$$

where $\gamma_{2}=l_{l} l_{f}+l_{l} l_{s}+l_{f} l_{s}, \gamma_{1}=r_{l} l_{f}+r_{f} l_{l}+r_{l} l_{s}+r_{s} l_{l}+$ $r_{f} l_{s}+r_{s} l_{f}$ and $\gamma_{0}=r_{l} r_{f}+r_{l} r_{s}+r_{f} r_{s}$. The equivalent power 
grid phase current is $I_{s d q}^{s^{\prime}}=I_{s d q}^{s}-I_{e d q}^{s}-I_{r d q}^{s \prime}$, wherein the parcels $I_{e d q}^{s}$ and $I_{r d q}^{s \prime}$ refer to the influence of the power grid and the system load respectively. If we consider the usual case where $Z_{s}<Z_{f}<Z_{l}$, the following simplification can be done:

$$
\begin{gathered}
\gamma_{2} \approx l_{l} l_{f}+l_{l} l_{s} \\
\gamma_{1} \approx r_{l} l_{f}+r_{f} l_{l}+r_{l} l_{s}+r_{s} l_{l} \\
\gamma_{0}=r_{l} r_{f}+r_{l} r_{s} .
\end{gathered}
$$

Therefore, the order of Equation (1) could be reduced, which results in

$$
G_{s}(s)=\frac{I_{s d q}^{s \prime}(s)}{V_{f d q}^{s}(s)}=-\frac{b_{s}}{s+a_{s}}
$$

where $b_{s}=\frac{1}{l_{f}+l_{s}}$ and $a_{s}=\frac{r_{f}+r_{s}}{l_{f}+l_{s}}$. In this model, parameters $r_{l}, l_{l}, \gamma_{2}, \gamma_{1}$ and $\gamma_{0}$ can vary as a function of the random behavior of nonlinear load or the grid impedances [14].

\section{CONTROL SCHEME}

Figure 3 presents the control block diagram for $S A P F$ based on the $B E B S$ methodology along with a flexible power quality compensation scheme. To enhance the performance of the $D C-l i n k$ and provide the flexibility of the reactive compensation, an estimation scheme (block Estimator) is introduced for obtaining the filter currents $\widehat{i}_{f d q}^{e}$, in $d q$ rotational frame of the power grid voltage vector. The $D C$-link voltage is regulated by a $P I$ controller with anti-windup. At the output of this controller is added the estimate of the system load current $\widehat{i}_{l d}^{e}$ (feedforward scheme $(F F)$ ) determined from the $S A P F$ current estimate $\widehat{i}_{f d}^{e}\left(\hat{i}_{l d}^{e}=i_{s d}^{e}-\widehat{i}_{f d}^{e}\right)$ for determining the reference current $i_{s d}^{e *}$. The correct value of this reference current guarantees the $S A P F$ energy balance. This one is also used in a control scheme to allow the reactive power compensation flexibility. For this purpose, it is introduced another control loop at $q$ axis that determines the reference current $i_{s q}^{e *}$. The phase angle of the power grid voltage vector $\left(\theta_{s}\right)$ is obtained by $P L L$ scheme. The reference currents $i_{f d q}^{e *}$ are converted to the stationary reference frame through orthogonal transformation $d q^{e}-d q^{s}$, implemented by block $x_{d q}^{e} / x_{d q}^{s}$.

\section{A. Filter Current Estimation}

The estimative of the filter currents can be calculated by

$$
\frac{\widehat{d i}_{f d q}^{e}}{d t}=\frac{1}{l_{f}}\left(v_{s d q}^{e}-v_{f d q}^{* e}-r_{f} \widehat{i}_{f d q}^{e}\right)
$$

This Equation is solved by using the Euler backward integration method due to its low complexity of implementation.

\section{B. DC-link Voltage Controller}

Figure 4 shows the block diagram of the DC-link voltage control loop. Block $R_{v}(s)$ refers to the standard $P I$ controller which transfer function is

$$
R_{v}(s)=\frac{K\left(1+s T_{i}\right)}{s T_{i}}
$$

where $K$ is the gain and $T_{i}$ is the integration time constant of the $P I$ controller. The algorithm of the $P I$ DC-link voltage controller is implemented with an anti-windup scheme. The delay introduced by the current control loop is neglected and its representation on this diagram is omitted (see Figure 4). To obtain a smooth current command $i_{f d}^{e}$ at the output of the DC-link voltage regulator, a first order low-pass filter is introduced in the DC-link voltage measurement, represented by block $G_{v}(s)$ given by

$$
G_{v}(s)=\frac{1}{1+\tau_{v} s}
$$

where $\tau_{v}$ is low-pass filter time constant used on the DClink voltage measurement. The term $\widetilde{i}_{f d}^{e}$ added in the controller output is a disturbance parcel related to the harmonic compensation (see Figure 4). The open loop transfer function of the DC-link can be given by

$$
G_{o r}(s)=\frac{K K_{\omega}\left(1+s T_{i}\right)}{s^{2} T_{i}(1+s T)}
$$

where $K_{\omega}=1 / C$ and $T=\tau_{v}$.

1) Design Criterion for the DC-link Voltage Controller - The design of the DC-link controller is determined by using the Symmetrical Optimum Tuning Optimization (SOTO) [14]. According to this, the suitable transfer function for a controller with two degrees of freedom is

$$
G_{s o}(s)=\frac{\omega_{o}^{2}\left(2 s+\omega_{o}\right)}{s^{2}\left(s+2 \omega_{o}\right)}
$$

where $\omega_{o}$ is the cutoff frequency of $G_{s o}(s)$. To make the transfer function $G_{\text {or }}(s)$ being identical to $G_{s o}(s)$ it is required that:

$$
\omega_{o}=\frac{1}{2 \tau_{v}}
$$

Thus, the controller gains can be given by

$$
\begin{aligned}
& K=\frac{C}{2 \tau_{v}}, \\
& T_{i}=4 \tau_{v} .
\end{aligned}
$$

2) Feedforward DC-link Control Scheme - The feedforward scheme is used to anticipate the DC-link controller action during the occurrence of severe load variations. This control scheme must generate at its output the power grid reference current $i_{s d}^{e *}$ that is given by

$$
i_{s d}^{e *}=i_{f d}^{e *}+i_{l d}^{e} .
$$

Since the load currents are not measured, the generation of the power grid reference current $i_{s d}^{e *}$ becomes dependent on the 


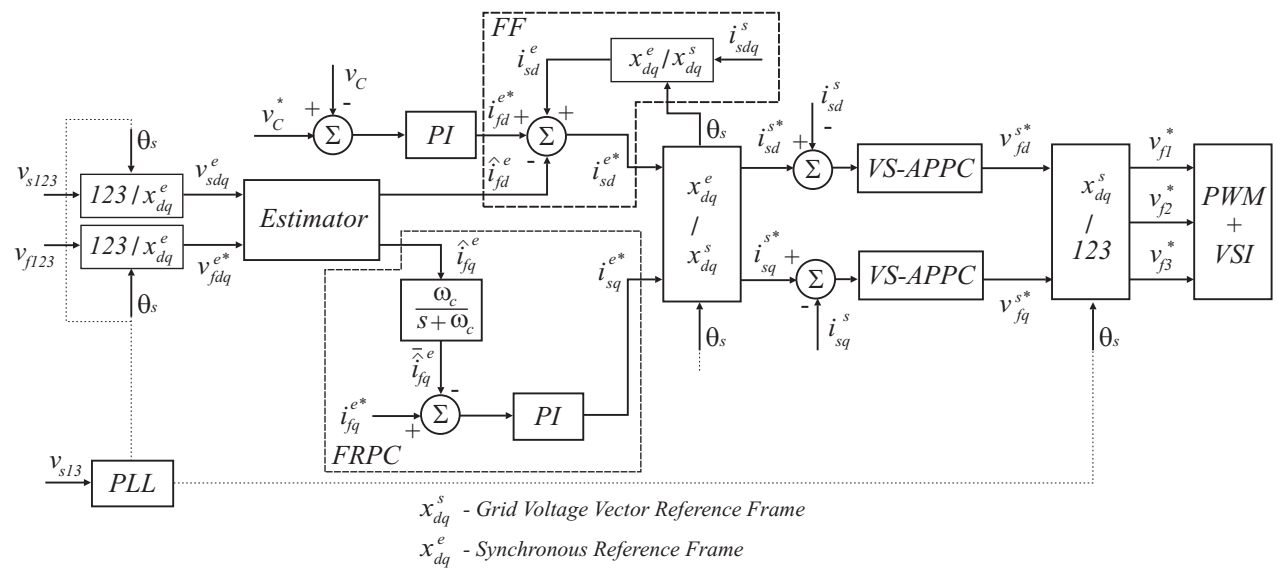

Fig. 3. Block diagram of the control strategy.

$S A P F$ energy balance, that generally has low time constant. To reduce this effect, the load current is estimated by using (6) and added to the $D C$ - link controller, which corresponds to the following

$$
i_{s d}^{e *}=i_{f d}^{e *}+\widehat{i}_{l d}^{e}
$$

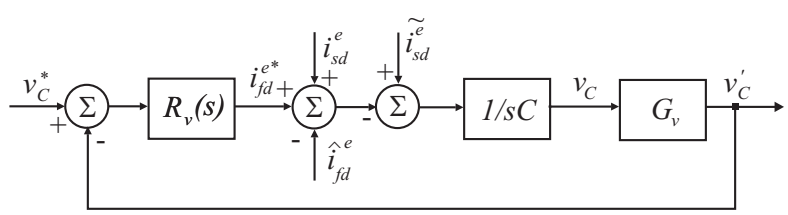

Fig. 4. Simplified block diagram of the $D C$ - link voltage control loop.

\section{Grid Currents Control Strategy}

The $d q$ phase currents of the power grid are indirectly regulated by $V S-A P P C$ controllers, whose application with $S A P F$ was introduced in [14]. From the $S A P F$ transfer function given by (5) whose parameters $a_{s}$ and $b_{s}$ are known with uncertainties. The aim of this strategy is to estimate these parameters for determining the gains of a suitable regulator such that closed loop poles are assigned to those of a Hurwitz polynomial $A_{s}^{*}(s)$ given by

$$
A_{s}^{*}(s)=s^{3}+\alpha_{2}^{*} s^{2}+\alpha_{1}^{*} s+\alpha_{0}^{*}
$$

where coefficients $\alpha_{2}^{*}=3 \omega_{i}, \alpha_{1}^{*}=3 \omega_{i}^{2}$ and $\alpha_{0}^{*}=\omega_{i}^{2}$, with $\omega_{i}$ being the desired controller bandwidth. Considering an arbitrary positive constant $a_{m}>0$, the grid currents can be estimated from

$$
\frac{\widehat{d i}_{s d q}^{s}}{d t}=-a_{m} \widehat{i}_{s d q}^{s}+\left(a_{m}-\widehat{a}_{s}\right) i_{s d q}^{s \prime}-\widehat{b}_{s} v_{f d q}^{s *}
$$

where $\widehat{a}_{s}$ and $\widehat{b}_{s}$ are estimates for $a_{s}$ and $b_{s}$, respectively. Defining the estimation error as

$$
\varepsilon_{0 d q}=i_{s d q}^{s}-\widehat{i}_{s d q}^{s}
$$

The parameters $a_{s}$ and $b_{s}$ can be estimated by using the following switching laws

$$
\widehat{a}_{s}=-\bar{a}_{s} \operatorname{sgn}\left(\varepsilon_{0 d q} i_{s d q}^{s}\right)
$$

$$
\widehat{b}_{s}=\bar{b}_{s} \operatorname{sgn}\left(\varepsilon_{0 d q} v_{f d q}^{s *}\right)+b_{s(n o m)}
$$

where $\operatorname{sgn}(x)$ is the signum function defined as

$$
\operatorname{sgn}(x):=\left\{\begin{array}{ccc}
-1 & \text { if } & x<0 \\
0 & \text { if } & x=0 \\
1 & \text { if } & x>0
\end{array} .\right.
$$

Assuming that stability constraints are satisfied $\bar{a}_{s}>\left|a_{s}\right|$ and $\bar{b}_{s}>\left|b_{s}-b_{s(\text { nom })}\right|$, with $b_{s(\text { nom })}$ being the nominal value of $b_{s}$.

Considering that phase currents of the power grid are regulated on the stationary reference frame, the transfer function of the $V S-A P P C$ controller is

$$
T_{s d q}(s)=\frac{\widehat{p}_{2} s^{2}+\widehat{p}_{1} s+\widehat{p}_{0}}{s^{2}+\omega_{s}^{* 2}}
$$

where $\omega_{s}^{*}$ is the power grid frequency and, $\widehat{p}_{2}, \widehat{p}_{1}$ and $\widehat{p}_{0}$ are the controller coefficients that can be determined as

$$
\begin{gathered}
\widehat{p}_{2}=\frac{\alpha_{2}^{*}-\widehat{a}_{s}}{\widehat{b}_{s}}, \\
\widehat{p}_{1}=\frac{\alpha_{1}^{*}-\omega_{s}^{* 2}}{\widehat{b}_{s}}, \\
\widehat{p}_{0}=\frac{\alpha_{0}^{*}-\omega_{s}^{* 2} \widehat{a}_{s}}{\widehat{b}_{s}} .
\end{gathered}
$$

The block diagram of the $V S-A P P C$ control algorithm for $S A P F$ current control loop is presented in Figure 5.

\section{Flexible Reactive Power Compensation}

The flexibility of the reactive power compensation is only possible if the load currents are measured which is not performed in $S A P F$ implemented with $B E B S$ methodology. However, this can be overcome through the use of filter current estimate $\widehat{i}_{f q}^{e}$ obtained from (6) and its estimate is given by

$$
\widehat{i}_{f q}^{e}=\overline{\hat{i}}_{f q}^{e}+\widetilde{\hat{i}}_{f q}^{e}
$$

where $\overline{\widehat{i}}_{f q}^{e}$ is the filter current term of the fundamental frequency and $\widetilde{\hat{i}}_{f q}^{e}$ is the harmonics parcel. 


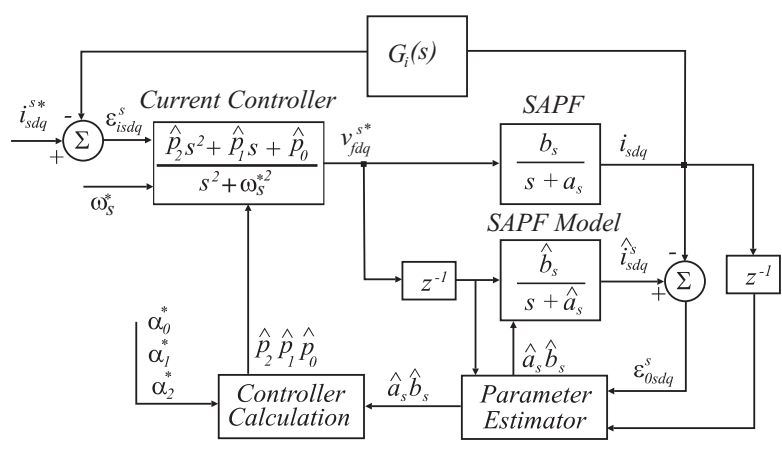

$V S-A P P C$

Fig. 5. Block diagram of the proposed $V S-A P P C$ current controller.

The parcel $\overline{\hat{i}}_{f q}^{e}$ regarding the load reactive power can be extracted from $\widehat{i}_{f q}^{e}$ by using a first order low-pass filter (LPF) given by

$$
G_{f r}(s)=\frac{\omega_{c}}{s+\omega_{c}} .
$$

The control loop scheme used for regulating the desired reactive power amount to be compensated is shown in the dashed box termed FRPC (flexible reactive power compensator) in the Figure 3. This control strategy can be better understood by using the simplified block diagram presented in Figure 6. In this block diagram, the delay introduced by the filter current control loop is neglected, and its representation is omitted. The block $1 / G_{s}(s)$ refers to the influence of $S A P F$ current model in the reactive control loop, wherein $G_{s}(s)$ is given by (5). The block $G_{e s}(s)=$ $1 /\left(s l_{f}+r_{f}\right)$ corresponds to the filter current estimator. A standard controller $P I$ is used to implement the FRPC.

1) Design of FRPC Controller - The open loop transfer function of this block diagram is

$$
G_{o r}(s)=\frac{\omega_{c}}{b_{s} l_{f}} \frac{\left(s+a_{s}\right)}{\left(s+a_{f}\right)\left(s+\omega_{c}\right)}
$$

where $a_{f}=\frac{r_{f}}{l_{f}}$.

The transfer function (28) has a second order dynamic determined by two poles and one zero. Considering the case where $Z_{s}<Z_{f}<Z_{l}$, the both poles, and zero are located in the $s$ left half plane. Whereas the pole $a_{f}$ is approximately equal to the zero $a_{s}$ and the constant $b_{s}$ is equal to $1 / l_{f}$, which permits the reduction of the order of transfer function $G_{o r}(s)$. Therefore the transfer function of Eq. (28), with the inclusion of $P I$ controller can be rewritten as

$$
G_{\text {ors }}(s)=\frac{k_{p c}\left(s+\frac{1}{\tau_{i c}}\right) \omega_{c}}{s\left(s+\omega_{c}\right)} .
$$

A possible design criterion for the $P I$ controller is to use the zero-pole canceling. By using this, the controller parameters are determined by making $\tau_{i c}=1 / \omega_{c}$ and choosing a controller gain $k_{p c}$ for a cutoff frequency of $\omega_{s}^{*} / 6$. With this control scheme and based on the $S A P F$ power rating, it is possible to define a criterion for defining the suitable amount of load reactive power that could be compensated.

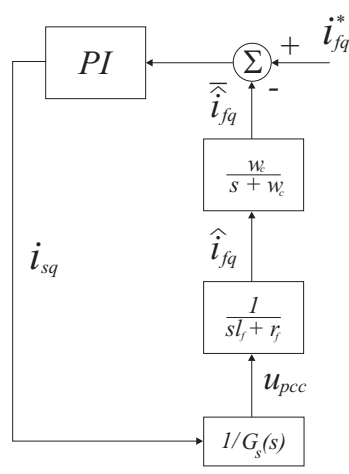

Fig. 6. Reduced block diagram of the reactive power control scheme.

2) Defining a Limit of Reactive Power Compensation - From the proposed scheme of reactive power flexibility, it is possible to define the limit of secure operation for the $S A P F$ inverter. Figure 7 shows the proposed scheme based on the definition of a limit for the $S A P F$ currents, defined by the current $i_{\text {fnom }}^{e}$ that represents the $S A P F$ nominal current in $d q$-frame.
Case I

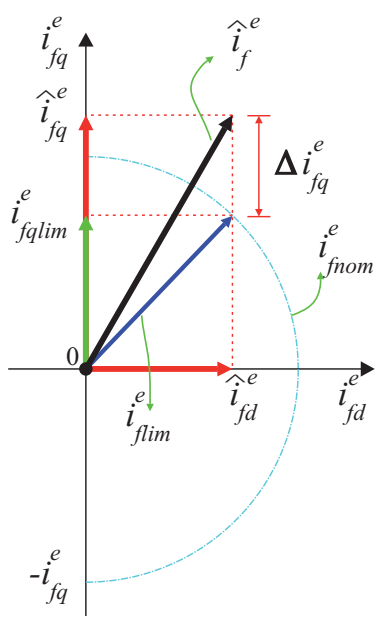

Case II

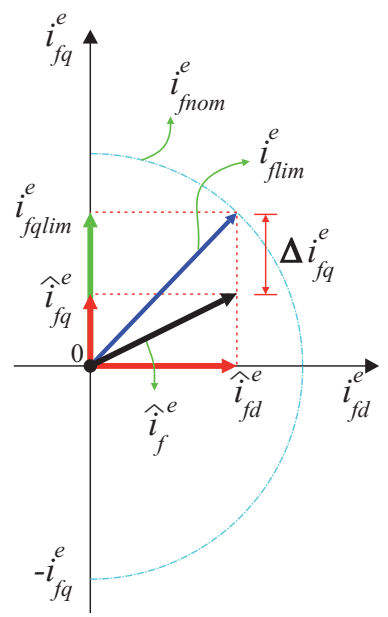

Fig. 7. Limit of reactive power compensation: (Case I) filter operating out of range and (Case II) filter with remaining power.

In the Figure 7 (case I) the $S A P F$ estimated currents represented by filter current vector $\widehat{i}_{f}^{e}$ is out of range. So, it is possible to reduce the reactive parcel $\left(\widehat{i}_{f q}^{e}\right)$ such that $S A F P$ currents become $i_{\text {flim }}^{e}$, that is within the boundary. Figure 7 (case II) represents the condition where there is remaining $S A F P$ power. In this case, depending on the application, it is possible to maintain the filter reactive parcel in this level or increase it up the power boundary. The parcel of $\Delta i_{f q}^{e}$ that must be reduced or increased (case I or case II) can be determined as a function of currents $\widehat{i}_{f q}^{e}$ and $i_{f q l i m}^{e}$ as:

$$
\Delta i_{f q}^{e}=\widehat{i}_{f q}^{e}-i_{f q \lim }^{e}
$$

Therefore, the reference current $i_{f q \text { lim }}^{e *}$, which determines the reactive power compensation can be obtained as

$$
i_{f q \lim }^{e *}=\widehat{i}_{f q}^{e} \pm \Delta i_{f q}^{e}
$$




\section{SIMULATION RESULTS}

This section presents the results of the proposed structure for reactive power with the flexibility approach. The proposed control system has been simulated by using PSIM. The system (Figure II) is composed by a three-phase power grid $\left(V_{s}=110 \mathrm{~V}(\mathrm{rms})\right)$ feeding a three-phase diode rectifier, connected to a $R L$ load $\left(r_{l}=10 \Omega\right.$ and $\left.l_{l}=30 \mathrm{mH}\right)$. The $S A P F$ DC-Link nominal voltage is $v_{c}=500 \mathrm{~V}$, and the filter inductors are $l_{f}=1.0 \mathrm{mH}$. For load transients, it was used a resistor $R=20 \Omega$ connected in parallel to the rectifier. Figure 8 presents the grid phase voltages $\left(v_{s 123}\right)$ under unbalanced conditions. Figure 9 shows the grid currents $\left(i_{s 123}\right)$ of a nonlinear load fed by the utility grid under the unbalanced conditions as in Figure 8. Notice that these results are without any $S A P F$ compensation.

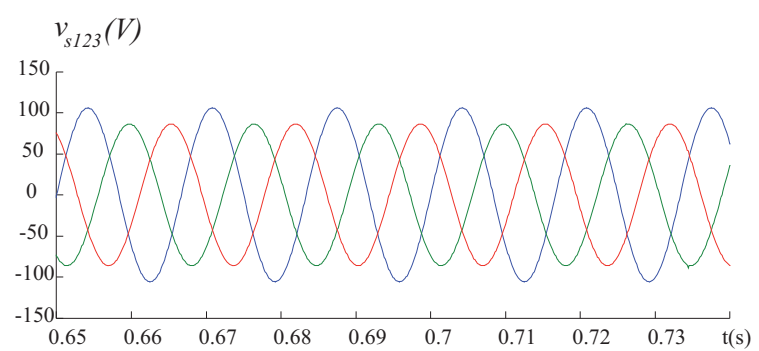

Fig. 8. Simulation results of the grid phase voltages $v_{s 123}$ under unbalanced conditions.

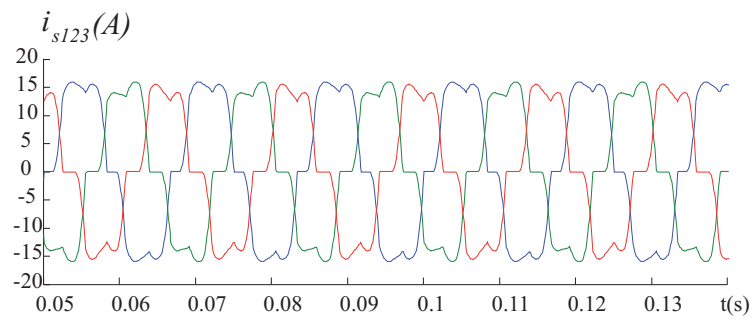

Fig. 9. Simulation results of the grid phase currents $i_{s 123}$ under unbalanced conditions previous any $S A F P$ compensation.

Figure 10 shows the grid currets $i_{s 123}$ during the $S A P F$ start-up. The stead-state grid currents $i_{s 123}$ with the compensation of the $S A P F$ is presented in the Figure 11. It is possible to see that unbalance of the load currents has been compensated by $S A P F$ due to the action of the $V S-A P P C$ current controller.

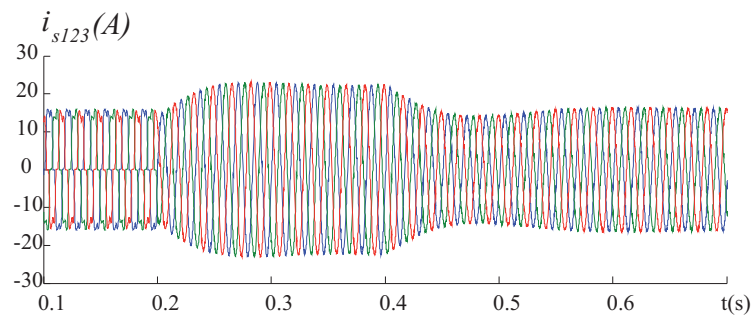

Fig. 10. Simulation results of the grid phase currents $i_{s 123}$ during the $S A F P$ Start-up under unbalanced conditions.

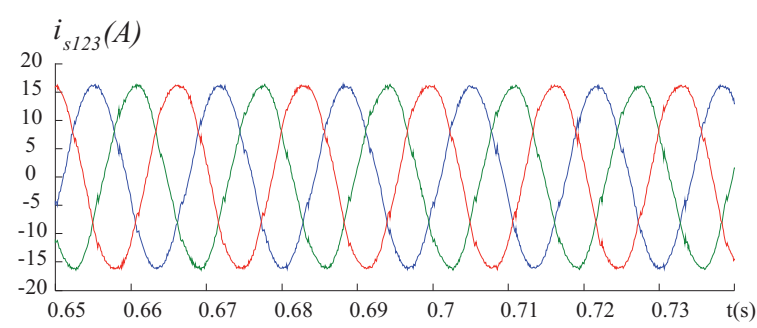

Fig. 11. Simulation results of the grid phase currents $i_{s 123}$ under unbalanced conditions after $S A F P$ compensation.

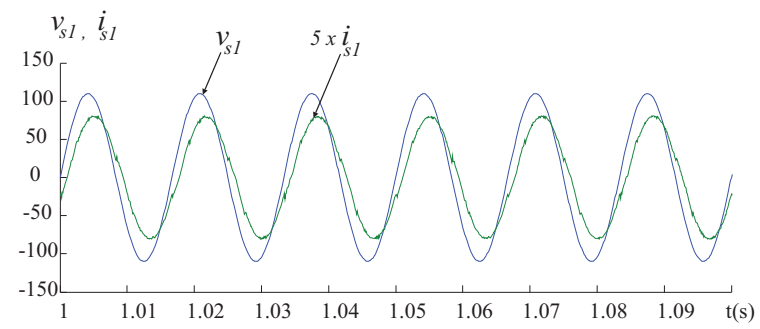

Fig. 12. Simulation results of the grid voltage and current $\left(v_{s 1}\right.$ and $\left.i_{s 1}\right)$ with flexibility.

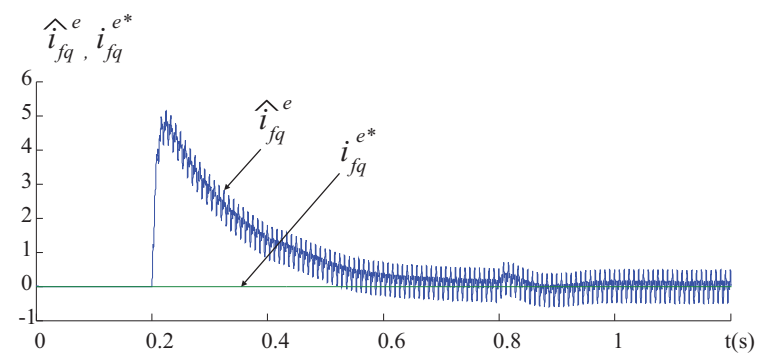

Fig. 13. Simulation results of the $S A P F$ estimated current $\widehat{i}_{f q}$ and its respective reference $i_{f q}^{e *}$.
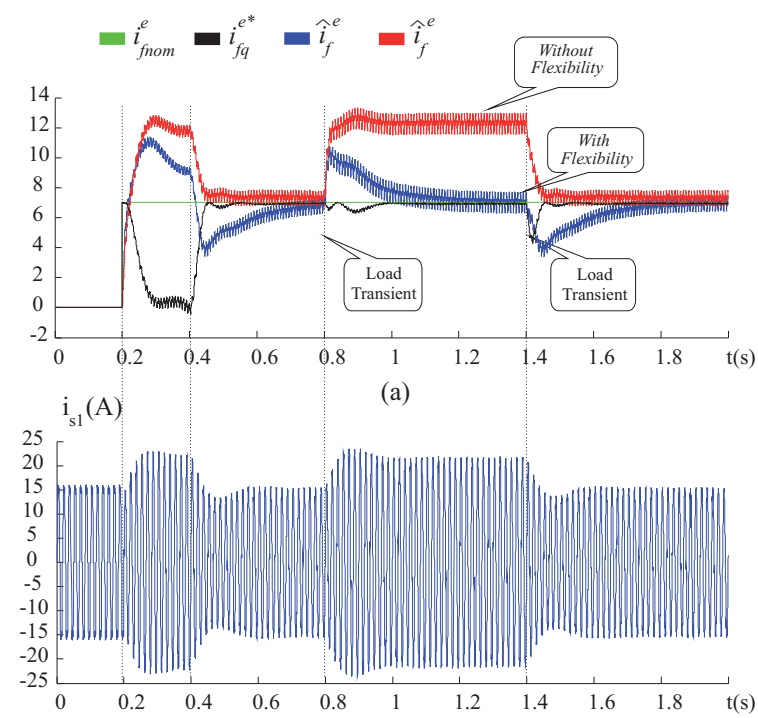

(b)

Fig. 14. Simulation results for the proposed scheme of reactive power compensation. 
Figure 12, however, highlights the flexibility scheme, which ends up with an intentional phase displacement $(P F=0.86$ inductive) between voltage and current. The dynamic of the $S A P F$ current $i_{f q}^{e}$ for the flexibility scheme is presented in the Figure 13.

Figure 14 presents a simulation results for the proposed scheme of limitation for reactive power compensation. In the Figure 14(a), the red line represents the $S A F P$ estimated current $\widehat{i}_{f}^{e}$ without flexibility, the blue line refers to current $\widehat{i}_{f}^{e}$ with flexibility, the green line means the nominal $S A P F$ current $i_{\text {fnom }}^{e}$ that defines the limit of reactive power compensation and finally, the black line represents the reference current $i_{f q}^{e *}$.

To demonstrate the proposed flexibility scheme, the $S A P F$ has been submitted to load transients. Figure 14(b) presents the grid current $i_{s 1}$. The first load transient happens at $t=0.8 \mathrm{~s}$ and consists in a step-up of the load current. It is possible verify in the Figure 14(a) that $S A F P$ estimated current $\widehat{i}_{f}^{e}$ (red line) increases and becomes bigger than its nominal value $i_{\text {fnom. }}^{e}$. This does not happen when the flexibility scheme is enabled. In this case, it is possible to see that current $\hat{i}_{f}^{e}$ (blue line) decreases down to $i_{f n o m}^{e}$. In this figure is also possible to verify that current $i_{f q}^{e *}$ changes dynamically to keep the $S A F P$ down to limit of compensation. At $t=1.4 \mathrm{~s}$ occurs a new transient, that consists in a step-down of the load current. After that, the $S A P F$ currents reach their steady-state condition.

\section{EXPERIMENTAL EVALUATION OF THE PROPOSED $S A P F$}

The proposed control system presented on Figure 3 has been evaluated experimentally by using a $10 \mathrm{~kW}$ three-phase active power filter laboratory prototype. It is composed by a three-phase power grid feeding a nonlinear load. The $V S I$ is connected to the $P C C$ by using input filter inductors $l_{f}=1.0$ $\mathrm{mH}$. The rated voltage of the $V S I$ DC-link is $450 \mathrm{~V}$. The nonlinear load is implemented by parallel association of a three-phase rectifier, feeding a $R L$ load $\left(r_{r}=30 \Omega\right.$ and $\left.l_{l}=50 \mathrm{mH}\right)$ and, a star connected $R L$ three-phase load $\left(r_{r}=100 \Omega\right.$ and $\left.l_{l}=200 \mathrm{mH}\right)$. The proposed control system was implemented on a TMS283335 digital signal processor $(D S P)$ platform. The $A / D$ converters of the $D S P$ card are connected to a measurement unit, composed by halleffect voltage and current sensors. The signal taken from these sensors pass through low-pass filters with a cutoff frequency of $f_{L P F}=2.5 \mathrm{kHz}$. The control algorithm is implemented in $C^{++}$and executed with a sampling time of $100 \mu \mathrm{s}$. For evaluating the performance of proposed $S A P F$, three groups of experimental tests are realized. They are DC-link voltage regulation with or without feedforward scheme, harmonic compensation, and flexible reactive power compensation. The $S A P F$ parameters of the laboratory prototype are provided in Table V.

\section{A. DC-link Voltage Control Scheme}

The performance of the proposed DC-link control scheme can be evaluated from the experimental results presented in Figures 15 to 17 . Figure 15 shows the experimental results of the soft starting procedure applied for the filter DC-link. In this
TABLE I

SAPF Parameters

\begin{tabular}{|c|c|}
\hline$V_{s}=110 \mathrm{~V}(\mathrm{rms})$ & $f_{s}=60 \mathrm{~Hz}$ \\
\hline$r_{s}=0.2 \Omega$ & $l_{s}=0.1 \mathrm{mH}$ \\
\hline$r_{f}=2 \Omega$ & $l_{f}=1 \mathrm{mH}$ \\
\hline$r_{l}=100 \Omega$ & $l_{l}=0.2 \mathrm{H}$ \\
\hline$\omega_{i}=170 \mathrm{rad} / \mathrm{s}$ & $a_{m}=15000$ \\
\hline $\bar{a}_{s}=2000$ & $\bar{b}_{s}=2000$ \\
\hline$b_{s(\text { nom })}=1500$ & $C=2200 \mu \mathrm{F}$ \\
\hline
\end{tabular}

graph, it is presented the superposition of the results obtained with a standard $P I$ control scheme (red line) and the results obtained with the proposed control strategy (black line) named here $P I+F F$. Initially, the capacitors of the filter $D C$ bus are charged by using an open loop control scheme until the voltage $v_{C}=220 \mathrm{~V}$. After this preload, the voltage of such capacitors is increased by using closed loop control scheme, which imposes a voltage ramp with derivative of $d v_{C} / d t=$ $347 \mathrm{~V} / \mathrm{s}$ until reaching the reference voltage of $v_{C}^{*}=450 \mathrm{~V}$. To evaluate the performance of the $P I+F F$ control strategy, the load currents are reduced suddenly by $50 \%$ of its rating value. This can be observed by the increase in the DC-link

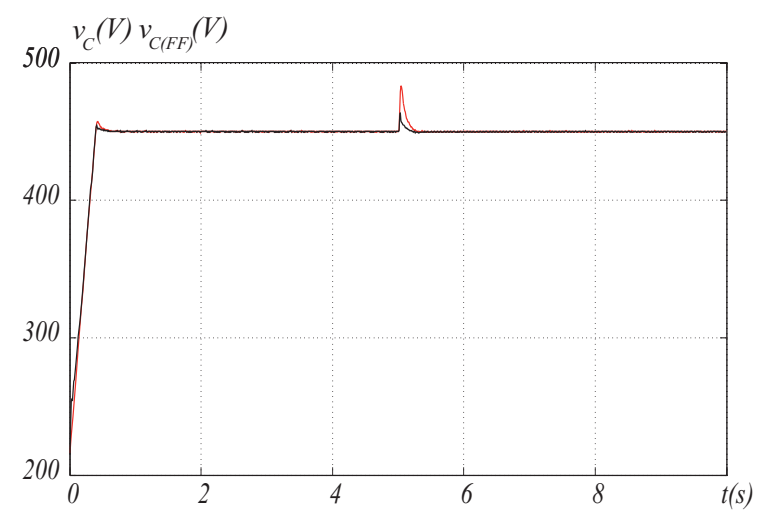

Fig. 15. Experimental results of DC-link during soft starting procedure.

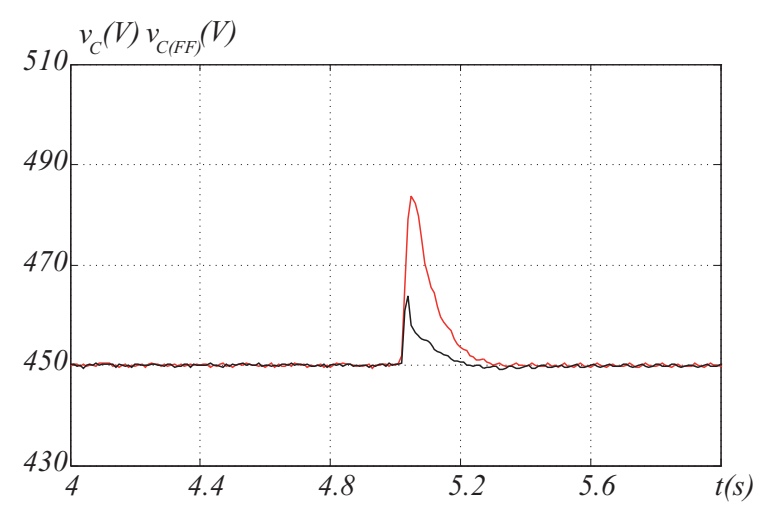

Fig. 16. Experimental results of DC-link during the reduction of load currents.

voltage occurred at time $t=5.0 \mathrm{~s}$. For better visualization, Figure 16 presents a zoom of this test during the occurrence 


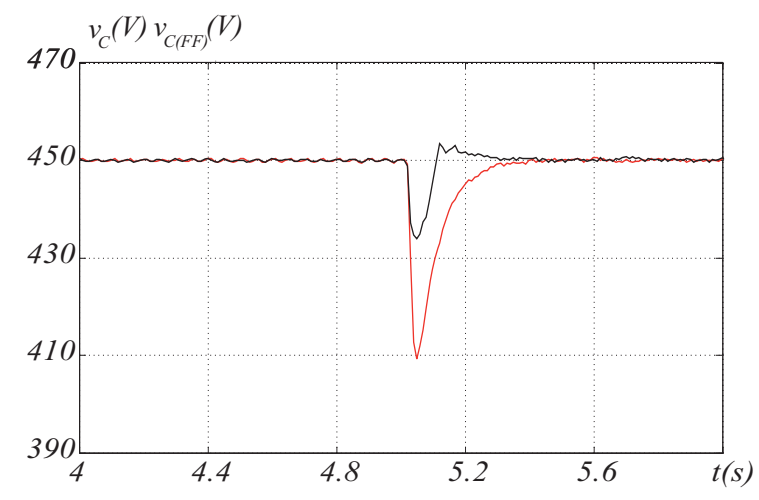

Fig. 17. Experimental results of DC-link during the increase of load currents.

of the load transient. When comparing the both strategies, it can be observed that proposed control scheme minimizes the voltage overshoot by $70 \%$ and also reduces the convergence time. It is also performed an experimental test with an increase of $50 \%$ in the load currents, which can be verified in Figure 17. As in the previous test, $P I+F F$ controller has showed better performance when compared to that implemented with standard $P I$ controller.

\section{B. Grid Current Control Strategy}

The effectiveness of the full compensation of harmonics and reactive power of the load can be verified on the experimental results presented in Figures 18 to 20. Figure 18 shows the experimental results of load currents. Figure 19 presents the grid phase currents after full power quality compensation. The harmonic content of the grid phase current $i_{s 1}$ is computed for three different cases, for evaluating the effectiveness of the proposed control scheme. The first refers to the grid current without any compensation scheme. The second is due to the

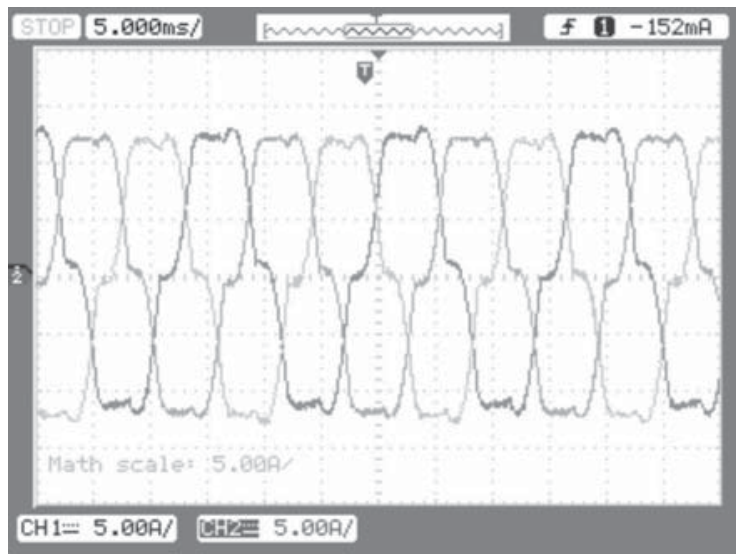

Fig. 18. Experimental results of grid phase currents before the introduction of the full power quality compensation.

full power quality compensation. The last one also refers to the full power quality compensation and the DC-link feedforward control strategy. These spectra are presented in Figure 20. In this figure, the dark spectrum is due the first case and the blue and red spectra are related to the second and third cases, respectively. Based on these graphs it can be noticed that
$S A P F$ reduces the harmonic content of the grid phase current, especially for $5^{\text {th }}$ and $7^{\text {th }}$ harmonic components.

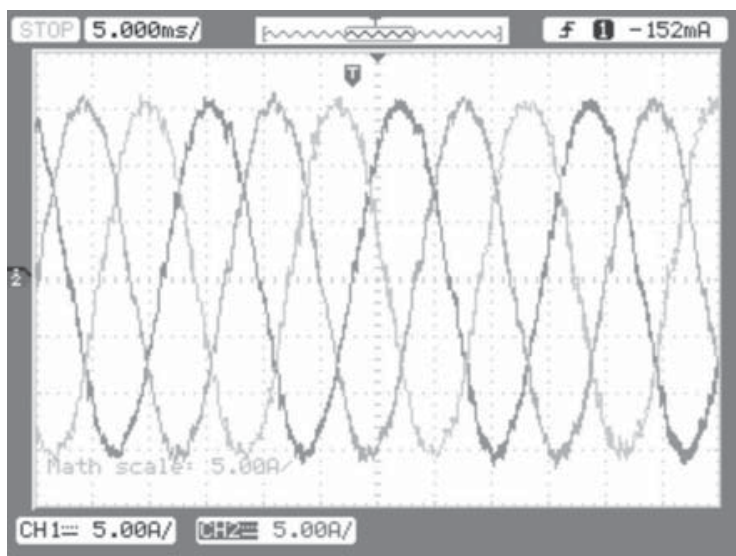

Fig. 19. Experimental results of grid phase currents after the introduction of the full power quality compensation.

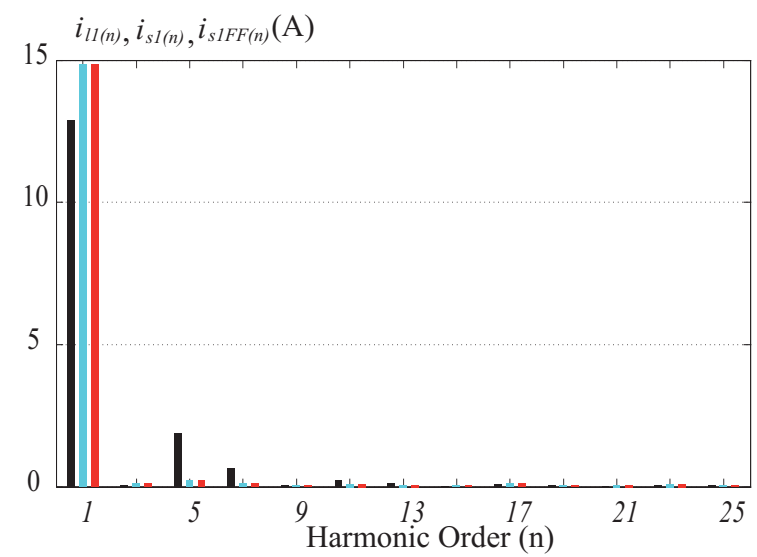

Fig. 20. Frequency spectra for the power grid phase current $i_{s 1}$ before and after full power quality compensation, and with the inclusion of $D C-$ link feedforward scheme.

Figures 21 to 23 show the oscilloscope screenshots with the results for the case where unbalanced voltages were imposed at the grid side. Before the compensation scheme, the harmonic distortion is $T H D_{i} \cong 24 \%$ (see Figure 21). After compensation, the grid phase currents present the harmonic distortion of $T H D_{i} \cong 3.5 \%$ (see Figure 22).

\section{Reactive Power Compensation Control Scheme}

The performance of the flexible reactive power compensation can be observed in Figures 24 to 26 . When the control strategy proposed in [14] is employed, both load harmonic distortion and load reactive power are fully compensated, as can be seen in Figure 24.

In this experimental results, we observe that resultant power factor is nearly unitary and the harmonic distortion is $T H D_{i} \cong$ $2.87 \%$. Two experimental tests are performed for evaluating the proposed control strategy for the $S A P F$ for reactive power compensation. In the first, the reference current $i_{f q}^{e *}$ is calculated such that system resultant power factor $(P F)$ is $P F=0.84$ inductive, with $T H D_{i} \cong 3.15 \%$ (see Figure 25 ). 


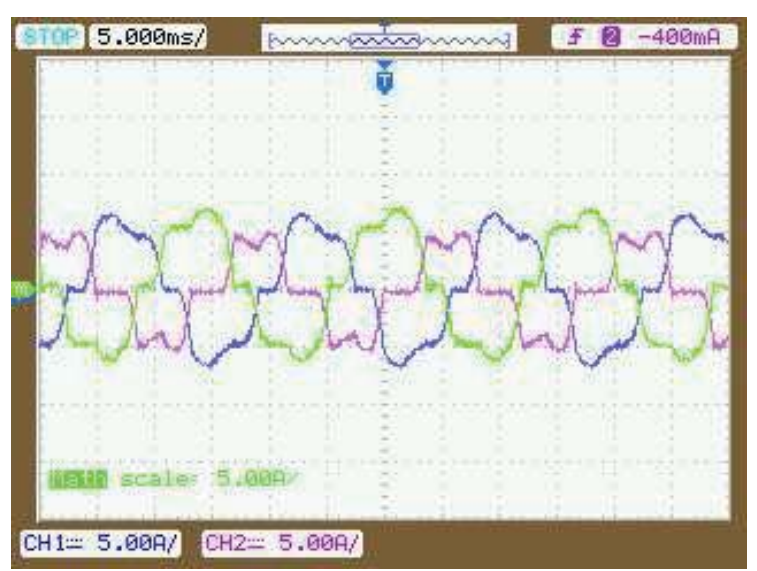

Fig. 21. Experimental results of the grid phase currents under unbalanced grid phase voltages, before the compensation scheme.

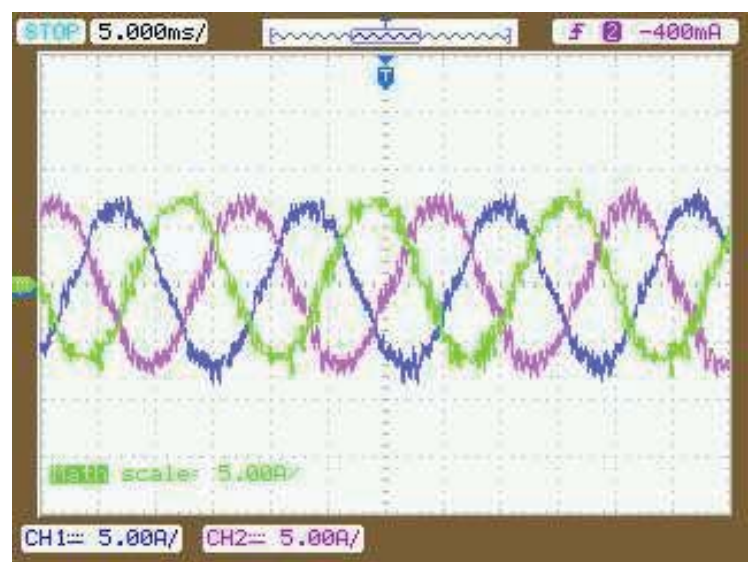

Fig. 22. Experimental results of the grid phase currents under unbalanced conditions of grid after compensation scheme.

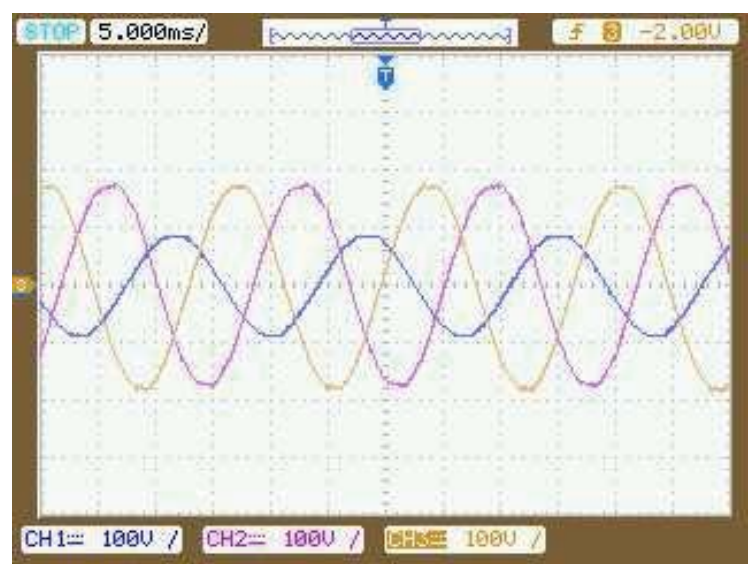

Fig. 23. Experimental results of the power grid phase voltages under unbalanced condition.

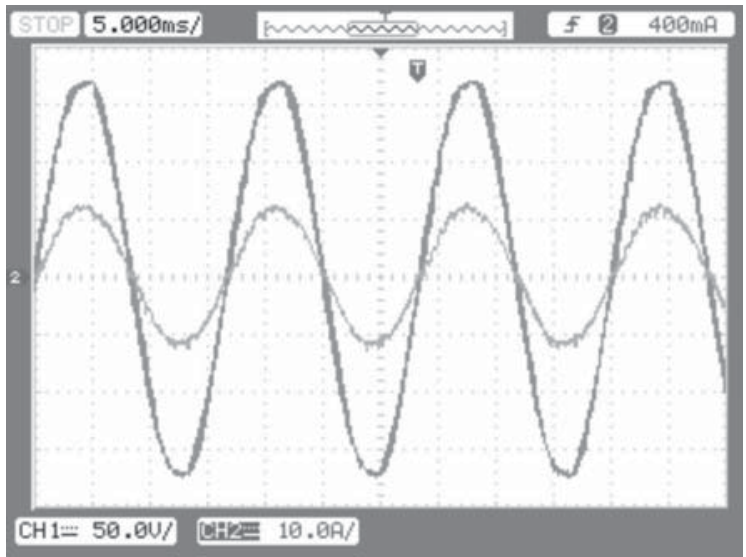

Fig. 24. Experimental results of the grid phase voltage $v_{s 1}$ and phase current $i_{s 1}$ for the flexible reactive power compensation (scales: $50 \mathrm{~V} /$ div and 10A/div for channels 1 and 2, respectively).

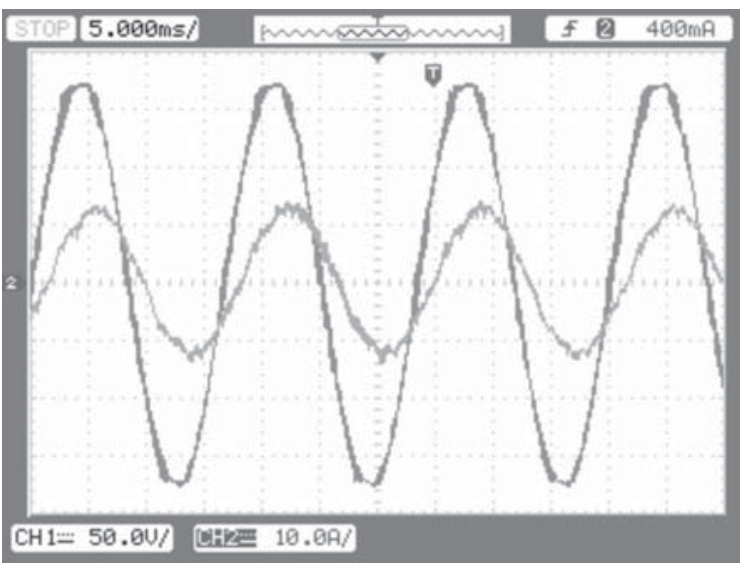

Fig. 25. Experimental results of the grid phase voltage $v_{s 1}$ and phase current $i_{s 1}$ for the flexible reactive power compensation (scales: $50 \mathrm{~V} / \mathrm{div}$ and 10A/div for channels 1 and 2 , respectively).

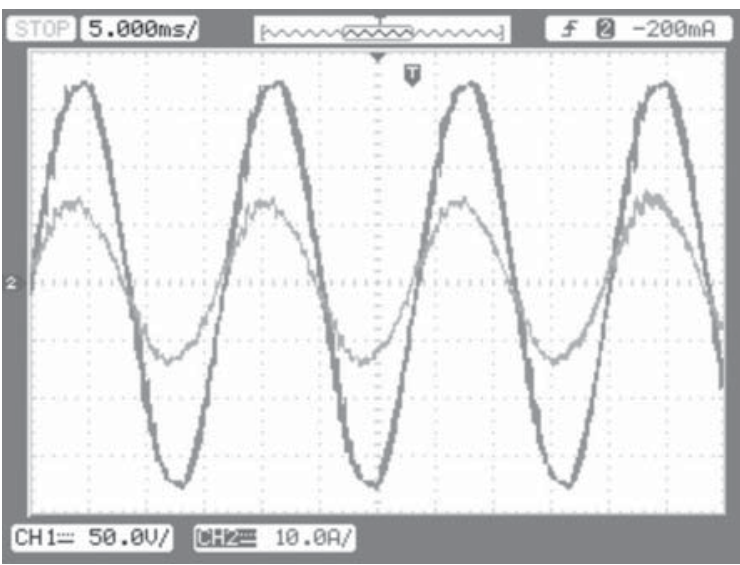

Fig. 26. Experimental results of the grid phase voltage $v_{s 1}$ and phase current $i_{s 1}$ for the flexible reactive power compensation (scales: $50 \mathrm{~V} /$ div and 10A/div for channels 1 and 2, respectively). 
In the second, $i_{f q}^{e *}$ is recalculated such that control strategy would impose a $P F=0.98$ capacitive, with $T H D_{i} \cong 3.02 \%$ (see Figure 26).

Figures 25 and 26 show the experimental results for these two tests. Analyzing them, we observe that proposed control strategy allows flexible control of system reactive power without degrading the $S A P F$ harmonic compensation. In order to verify this, the measurement of the harmonic distortion of both tests were performed, which has been resulted in similar a current distortion.
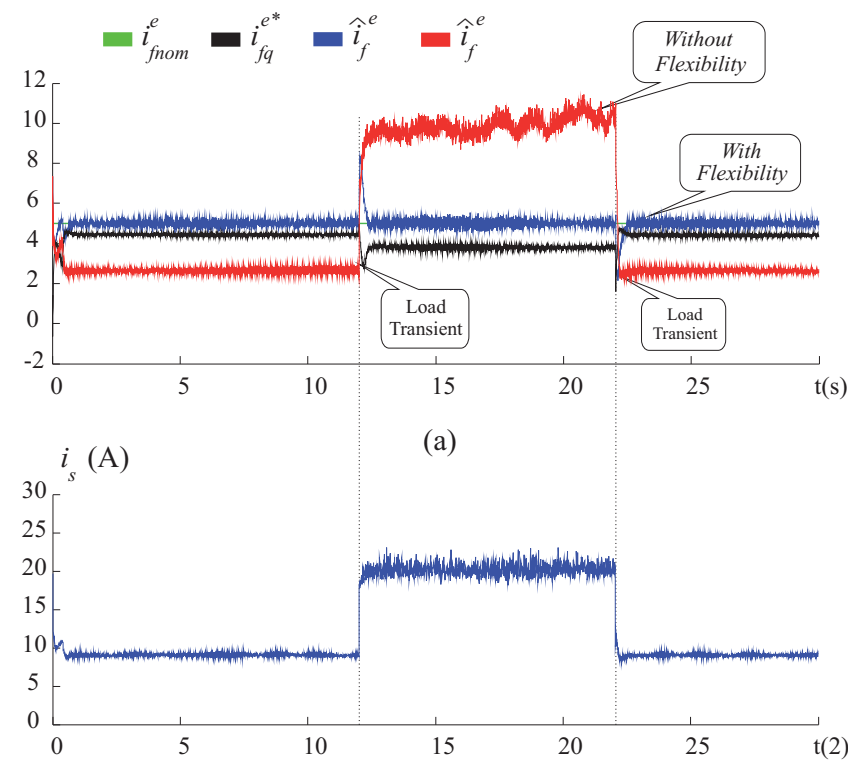

(b)

Fig. 27. Experimental results for the proposed scheme of reactive power compensation: (a) details of flexibility scheme and (b) PCC phase current $i_{s 1}$ during the load transient.

Figure 27 shows the experimental results for the proposed flexibility scheme. In Figure 27(a), it is possible to verify that inside the time interval $0<t<12 s$, the $S A P F$ current $\hat{i}_{f}^{e}$ without flexibility strategy (red line) is under the defined current limit $i_{\text {fnom }}^{e}=5 \mathrm{~A}$. This experimental result refers to the case where there is a remaining power. As stated before, it is possible to maintain the reactive parcel in this level or increase it. In this experiment, it is employed the last option. For that reason, the value of reference current $i_{f q}^{e *}$ (black line) is increased. This means that $S A P F$ injects more reactive power in the system and consequently, the current $\hat{i}_{f}^{e}$ is closed to $i_{\text {fnom. }}^{e}$. In the time instant $t=12 s$, it is introduced a load transient as can be observed in the graphic of the source current $i_{s}$. After this transient, it is possible to notice that load demands a higher power from the $S A P F$ to compensate harmonics and reactive power. Without the flexibility scheme, the current $\widehat{i}_{f}^{e}$ (Red line) becomes greater than the filter nominal value $i_{\text {fnom. }}^{e}$. In this case, for accomplishing the filter power boundary limits, it required to reduce the current $\widehat{i}_{f}^{e}$ for assuring the secure operation. Finally, in time instant $t=22 \mathrm{~s}$, the load current is reduced and the filter returns to its initial operational conditions.

\section{CONCLUSIONS}

This paper presents some contributions for improving the $S A P F$ operation with $B E B S$ methodology. For this purpose, it is used a feedforward scheme to enhance the performance of the $D C-l i n k$ voltage control loop during load variations. It is also proposed a scheme that allows the flexibility of the system reactive power compensation, observing the $S A P F$ security limit operation. Both benefits have been obtained by introducing an estimation scheme for determining the load phase currents. These changes incorporated in this work enable the complete equivalence of $S A P F s$ implemented with $B E B S$ or $H E B S$ methodologies. In addition, proposed control scheme gives a significant gain in the $S A P F$ based on the $B E B S$, because the current control strategy is simpler and employs a reduced number of current sensors. Experimental results demonstrate that proposed control strategy is effective in reducing the harmonic distortion, immune to load variations and allows the flexibility of reactive compensation.

\section{ACKNOWLEDGEMENT}

The authors wish to thank the National Council of Technological and Scientific Development $(C N P q)$ for the financial support.

\section{REFERENCES}

[1] CEI/IEC. IEC 61000-3-2 International Standard. International Eletromechanical Commission, 1998.

[2] IEEE. IEEE P519.1/D12 Draft Guide for Applying Harmonic Limits on Power Systems. IEEE Standard, 2012.

[3] H. Akagi. Trends in active power line conditioners. IEEE Transactions on Power Electronics, 9(3):263-268, May 1994.

[4] B. Singh and V. Verma. Selective compensation of powerquality problems through active power filter by current decomposition. IEEE Transactions on Power Delivery, 23(2):782-799, Apr. 2008.

[5] B. Singh, K. Al-Haddad, and A. Chandra. A review of active filters for power quality improvements. IEEE Transactions on Industry Electronics, 46(5):960-971, Oct. 1999.

[6] A. Bhattacharya and C. Chakraborty. A shunt active power filter with enhanced performance using ann-based predictive and adaptive controllers. IEEE Transactions on Industry Electronics, 58(2):421-428, Feb. 2011.

[7] S. Bhattacharya, T. M. Frank, D. M. Divan, and B. Banerjee. Active filter system implementation. IEEE Industry Application Magazine, 4(5):47-63, Sep./Oct. 1998.

[8] F. Z. Peng, G. W. Ott. Jr., and D. J. Adams. Harmonic and reactive power compensation based on the generalized instantaneous reactive power theory for three phase four wire system. IEEE Transactions on Power Electronics, 13(6):1174-1181, Nov. 1998.

[9] H. Karimi, M. Karimi-Ghartemani, and M. R. Iravani. An adaptive filter for synchronous extraction of harmonics and distortions. IEEE Transactions on Power Delivery, 18(4):1350-1356, Oct. 2003. 
[10] M. Forghani and S. Afsharnia. Online wavelet transformbased control strategy for upqc control system. IEEE Transactions on Power Delivery, 22(1):481-491, Jan. 2007.

[11] P. Kumar and A. Mahajan. Soft computing techniques for the control of an active power filter. IEEE Transactions on Power Delivery, 24(1):452-461, Jan. 2009.

[12] A. Bhattacharya, C. Chakraborty, and S. Bhattacharya. Current compensation in shunt type active power filters. IEEE Industrial Electronics Magazine, 3(3):38 - 49, Sep. 2009.

[13] T. E. Nunez-Zuniga and J. A. Pomilio. Filtro ativo de potência sintetizando cargas resistivas. Eletrônica de Potência - SOBRAEP, 5(1):35-42, May 2000.

[14] R.L.A. Ribeiro, C.C. Azevedo, and R.M. Sousa. A robust adaptive control strategy of active power filters for power-factor correction, harmonic compensation, and balancing of nonlinear loads. IEEE Transactions on Power Electronics, 27(2):718-730, Feb. 2012.

[15] W. Longhui, Z. Fang, Z. Pengbo, L. Hongyu, and W. Zhaoan. Study on the influence of supplyvoltage fluctuation on shunt active power filter. IEEE Transactions on Power Delivery, 22(3):1743-1749, July 2007.

[16] Chi-Seng Lam, Wai-Hei Choi, Man-Chung Wong, and Ying-Duo Han. Adaptive dc-link voltagecontrolled hybrid active power filters for reactive power compensation. IEEE Transactions on Power Electronics, 27(4):1758-1772, Apr. 2012.

[17] M. J. Newman, D. N. Zmood, and D. G. Holmes. Stationary frame harmonic reference generation for active filter systems. IEEE Transactions on Industry Applications, 38(6):1591-1599, Nov./Dec. 2002.

[18] L. Malesani, P. Matavelli, and S. Buso. Robust deadbeat current control for pwm rectifiers and active filters. IEEE Transactions on Industry Applications, 35(3):613620, May/Jun. 1999.

[19] B. Singh, K. AI-Haddad, and A. Chandra. Active power filter with sliding mode control. IEE Proceedings Generation, Transmission and Distribution, 144(6):564568, Nov. 1997.

[20] R.R. Pereira, C.H. da Silva, L.E. Borges da Silva, G. Lambert-Torres, and B. K. Bose. Adaptive hysteresis current control of a pwm inverter at constant modulation frequency applied to shunt active power filters. Eletrônica de Potência - SOBRAEP, 15(4):323-329, Nov 2010.

[21] L. R. Limongi, D. Roiu, R. Bojoi, and A. Tenconi. Frequency-domain analysis of resonant current controllers for active power filters. Eletrônica de Potência - SOBRAEP, 15(4):294-304, Nov 2010.

[22] P. Mattavelli and F. P. Marafao. Repetitive-based control for selective harmonic compensation in active power filters. IEEE Transactions on Industry Electronics, 51(5):1018 - 1024, Oct. 2004.

\section{BIOGRAPHIES}

Ricardo Lucio de Araujo Ribeiro was born in Campina Grande, Paraiba, Brazil, in 1961. He received the
B.C.E.E.,M.S.E.E., and D.Sc. degrees, all in electrical engineering, from the Federal University of Paraiba, Campina Grande, Brazil, in 1990, 1992, and 2003, respectively. In 2004, he joined the staff of the Department of Electrical Engineering, the Federal University of Rio Grande do Norte, Natal, Brazil, where he is currently a Professor of Electrical Engineering and the Direc- tor of the Research Laboratory on Power Electronics and Renewable Energy. His research interests include electrical drives, power electronics, active power filter, and renewable energy.

Raphaell Maciel de Sousa was born in Sao Paulo, Brazil, in 1986. He is graduated in industrial automation from the Federal Institute of Paraiba, Cajazeiras, Brazil, in 2008. He received the M.S. degree in electrical engineering from Federal University of Rio Grande do Norte, Natal, Brazil, in 2011, where he is currently working toward the Ph.D. degree. Since 2009, he has been a Faculty Member of the Federal Institute of Paraiba. His research interests include power electronics, electrical drives, and active power filter.

Euzeli Cipriano dos Santos Jr. received the B.S.,M.S., and $\mathrm{Ph} . \mathrm{D}$. degrees in Electrical Engineering from the Federal University of Campina Grande, Campina Grande, Brazil, in 2004, 2005, and 2007, respectively. From 2006 to 2007, he was with Electric Machines and Power Electronics Laboratory, Texas A\&M University, College Station, as a Visiting Scholar. From December 2010 to March 2011 he was a visiting professor at the University of Siegen, Germany. From 2007 to 2009 he was with the Federal Institute of Education, Science and Technology of Paraiba. From 2009 to 2012, he was with the Department of Electrical Engineering, Federal University of Campina Grande, as a professor of electrical engineering. Since July 2012 he has been with the Indiana University-Purdue University Indianapolis (IUPUI), where he is now an assistant professor of electrical engineering. His research interests include power electronics, electrical drives and renewable energy systems. He is a Member of SOBRAEP and an IEEE Senior Member.

Thiago de Oliveira Alves Rocha was born in Natal, Rio Grande do Norte, in 1986. He received the B.S., M.S. degrees in electrical engineering from the Federal University of Rio Grande do Norte, Brazil, in 2011 and 2013, respectively, where is currently working toward the Ph.D. degree. Since 2014, he has been a Faculty Member of the Federal Institute of Rio Grande do Norte. His research interests include electrical drives, power electronics, active power filter, and renewable energy. 